\title{
Obituário Professor Oswaldo Paulo Forattini, Médico, Epidemiologista e Entomologista
}

No dia 15 de setembro de 2007, o Brasil perdeu um dos cientista de maior liderança no campo da Saúde Pública e Entomologia Médica, Professor Oswaldo Paulo Forattini (83 anos), em São Paulo.

Professor Forattini, argentino naturalizado brasileiro, foi filho único de pais imigrantes do norte da Itália que chegaram ao Brasil no início da década de 1920. Cresceu em ambiente familiar, onde falava português com o pai e francês e italiano com a mãe, Josefina. Além de dominar com fluência as três línguas, Professor Forattini estudou latim, tornando-se fluente em Português, Espanhol, Francês, Italiano e Inglês.

Professor Forattini foi um apaixonado por literatura, história, música clássica e artes. Desde muito jovem ia a concertos no Teatro Municipal de São Paulo aos domingos pela manhã. Durante o curso colegial, pensava em estudar história, mas com o passar dos anos decidiu fazer vestibular para o curso de medicina, tornando-se aluno da Faculdade de Medicina da Universidade de São Paulo.

Enquanto aluno do curso de medicina, rapidamente se envolveu em pesquisas, publicando seis artigos em 1946 e outros cinco em 1947. Como reconhecimento ao trabalho intitulado "Esquistossomose Mansônica em Santos, Estado de São PauIo" que desenvolveu para a disciplina " $\mathrm{Ca}$ deira de Higiene da Faculdade de Medicina", o Professor Forattini recebeu o Prêmio Emílio Ribas no ano de 1947. Logo depois de se formar em medicina, em 1949, Forattini ingressou na então Faculdade de Higiene e Saúde Pública da Universidade de São Paulo como professor assistente do Departamento de Parasitologia e Higiene Rural. Teve início assim sua carreira universitária. Iniciou estudos em entomologia médica em 1950, com o pesquisador John Lane, e depois saúde pública, em 1957. Em
1959 submeteu-se a concurso para provimento do cargo de Professor Adjunto da Cadeira de Parasitologia Aplicada e Higiene Rural. Foi em 1967 que o Professor Forattini conquistou a Cátedra em Epidemiologia, e em 1970 assumiu a chefia do Departamento de Epidemiologia.

Professor Forattini teve vida científica bastante produtiva. Nesse sentido, suas contribuições tanto para o desenvolvimento da ciência no Brasil como na Universidade de São Paulo foram de enorme relevância, tendo merecido o reconhecimento e respeito nacional e internacional. Publicou mais de uma centena de artigos e alguns livros, associando a ecologia aos estudos dos insetos de interesse médico e agravos à saúde do homem. Entre suas contribuições científicas para o desenvolvimento da Entomologia Médica no Brasil e América Latina incluem-se mais de 200 artigos científicos, a maioria na área de epidemiologia médico-entomológica, em colaboração com alunos e colegas do Brasil e do exterior. Paralelamente, teve 13 livros publicados. Entre eles, quatro são considerados clássicos da entomologia médica da Região Neotropical, escritos na década de 1960 e início da de 1970. São eles:

Forattini, O.P. - Entomologia médica. Parte geral, Diptera, Anophelini. v. 1, São Paulo, Faculdade de Saúde Pública da USP, 1962.

Forattini, O.P. - Entomologia médica. Culicini: Culex, Aedes e Psorophora. v. 2, São Paulo, Ed. da Universidade de São Paulo, 1965.

Forattini, O.P. - Entomologia médica. Culicini: Haemagogus, Mansonia, Culiseta, Sabethini, Toxorhynchitini, Arboviroses, 
Filariose bancroftiana, Genética. v. 3, São Paulo, Ed. da Universidade de São Paulo, 1965.

Forattini, O.P. - Entomologia médica. Psychodidae, Phlebotominae, Leishmanioses, Bartonelose. v. 4, São Paulo, Ed. Edgard Blücher/Ed. Univ. S.Paulo, 1973.

Como conseqüência de uma vida dedicada à produção de conhecimentos científicos, Professor Forattini foi agraciado com múltiplos prêmios. Merecem destaque os prêmios: Emílio Ribas (Esquitossomose mansônica em Santos, Estado de São Paulo, 1947); José Pinto Alves (Contribuição para o estudo da actinomicose toraco-pulmonar, 1948); Florêncio Gomes da Academia de Medicina de São Paulo (Culicoides Neotropicais (Diptera, Ceratopogonidae, 1955); Contribuição Relevante para a Pesquisa da Universidade de São Paulo (1992); John Belkin Memorial" do American Mosquito Control Association, EUA (1995); Jabuti pelo seu livro Culicidologia Médica.
Vol. 1. (1996) e Câmara Brasileira do Livro (1997). Recebeu a Medalha Cultural Gaspar Vianna, em 1961, por sua contribuição aos estudos relativos à leishmaniose tegumentar. Em 2005, recebeu o título de Professor Emérito da Faculdade de Saúde Pública da Universidade de São Paulo.

Outra contribuição relevante do Professor foi a formação de alunos de graduação e pós- graduação e de pesquisadores. Muitos de seus alunos hoje atuam em diferentes áreas da entomologia médica no Brasil e América Latina, como pesquisadores ou professores universitários. Dessa maneira, ele foi capaz de formar seguidores que darão continuidade à entomologia médica na região neotropical.

Maria Anice Mureb Sallum, Departamento de Epidemiologia, Faculdade de Saúde Pública, Universidade de São Paulo 